\title{
Mirror-image stimulation and short separations in stumptail monkeys
}

\author{
JAMES R. ANDERSON \\ University of Stirling, Stirling, Scotland
}

\begin{abstract}
Two experiments examined the responses of infant stumptail macaques (Macaca arctoides) to mirror-image stimulation (MIS) during short social separations. Overall, infants living in pairs showed agitation when separated from their partners, but were calmer when the partner, an unfamiliar peer, or their own mirror image was visible. MIS elicited more facial expressions than the familiar peer, and more affiliative contact than an unfamiliar peer. In contrast, infants reared in a group were not calmed during separations either by an unfamiliar peer or by MIS, and they exhibited some negative reactions to the mirror. Social responsiveness to MIS varies with the social background of the subjects.
\end{abstract}

Mirror-image stimulation (MIS), that is, "situations in which an animal is confronted with its reflected image" (Gallup, 1968, p. 782), has been featured in numerous analyses of motivational and social phenomena in animals, for example, social facilitation in birds and rodents (e.g., Hamrick, Cogan, \& Woolam, 1971), visual reinforcement and aggression in birds and fish (e.g., Cohen \& Looney, 1973; Davis, Harris, \& Shelby, 1974; Dore, Lefebvre, \& Ducharme, 1978; Gallup \& Capper, 1970), tonic immobility and egg-laying in birds (Gallup, 1972; Lott \& Brody, 1966), and social responsiveness in rodents (Svendsen \& Armitage, 1973). These studies indicate that MIS has social-stimulus properties (see Gallup, 1968), and the more recent studies also demonstrate differing reactions to mirrors and other individuals.

Studies with primates have shown visual reinforcement using MIS and have shown that chimpanzees and orangutans recognize themselves in mirrors, whereas monkeys show a persistent social orientation toward their own reflections, despite extensive experience with MIS (reviews: Anderson, in press; Gallup, 1982).

Although exploratory responses and social displays to mirrors are documented for nonhuman primates, the range of social phenomena that MIS can support in monkeys has received little attention. The degree to which a monkey's own reflection perceptually resembles another monkey remains poorly un-

\footnotetext{
This research was conducted while the author was in receipt of a postgraduate research studentship from the U.K. Science Research Council. The computer program for analysis of paper tapes was written with support from S.R.C. Grant B/RG 98910 to A. Chamove, who commented on the manuscript. The author is also grateful to F. Bayart for assistance with Experiment 2, to V. Nash for computing, and to $M$. Harrison and $W$. McGrew for comments. The author's address is: Psychology Primate Unit, University of Stirling, Stirling FK9 4LA, Scotland.
}

derstood. Here I report two experiments, which used peer-separation methods to determine the extent to which self-images are perceived as others by stumptail monkeys.

\section{EXPERIMENT 1}

In assessing the social stimulus properties of MIS with domestic chicks, Gallup, Montevecchi, \& Swanson (1972) found that MIS was three times as effective as a peer behind a clear partition in lowering the frequency of peep vocalizations in chicks separated from their peers. Chicks were also calmer if fear-evoking stimuli were presented in the presence of a mirror than with no social companion present (Montevecchi, Gallup, \& Dunlap, 1973).

Infant monkeys housed together form social attachments (Chamove, 1973) and show behavioral disruption if separated from each other (Suomi, Harlow, \& Domek, 1970). If a mirror could reduce separation-induced agitation in infant monkeys removed from their peers, it would increase the generality of Gallup's (1968) contention that a variety of mirror-mediated social phenomena should be seen in species that show social responses to their own reflections. The influence of the distance of the subject from the mirror was also examined.

\section{Method}

Subjects. The subjects were four laboratory-born, mirror-naive infant stumptail macaques (Macaca arctiodes), three males and one female. They had been living as two pairs for 2 and 4 months (mean ages 8.8 and 11.2 months, respectively) following removal from their natal group. Each pair lived in a steel mesh cage measuring $65 \times 60 \times 59 \mathrm{~cm}$, with food, water, and toys always available.

Apparatus. Testing took place in a rectangular cage measuring $350 \mathrm{~cm}$ long $\times 75 \mathrm{~cm}$ wide $\times 125 \mathrm{~cm}$ high. The cage could be divided into four equal sections by inserting three transparent Perspex partitions. An opaque white partition prevented the subjects from seeing into the leftmost section, which was never used to hold any 
subjects, but which sometimes contained a $90 \times 90 \mathrm{~cm}$ mirror (see below). During mirror-present tests, the mirror was positioned in the leftmost cage section, just behind the clear Perspex partition and facing the rest of the cage. Water and two familiar toys were available to the subjects during tests. Behavioral data were recorded on a 12-key keyboard connected to a small device that displayed the cumulative duration of individual keypresses and frequency of presses for four of the keys.

Procedure. The subjects were well acquainted with the testing cage, which had often served as a playcage. There were 3 consecutive days of testing with each pair, with five short separations occurring each day as follows: The monkeys were put into one section of the cage and left together to behave freely for $1 \mathrm{~h}$, during which the white partition prevented their seeing into the leftmost section. Then the series of five separations began. "Partial" separations were achieved by partly withdrawing one of the transparent partitions and reinserting it when one of the animals had crossed into the neighboring cage section, leaving the partners physically but not visually separated. "Total" separations involved removing one of the pair to the home cage. Then, while the subject remained in the testing cage, the white partition was withdrawn to reveal the empty leftmost cage section. "Mirror-near" separations were the same as total separations except that the white partition was removed to reveal the mirror on the other side of the transparent partition, $2.5 \mathrm{~cm}$ away. In "mirror-intermediate" separations, the subject was confined in the cage section next but one to the mirror (i.e., $90 \mathrm{~cm}$ from the mirror), and in "mirrorfar" separations, the subject was in the farthest section from the mirror $(167.3 \mathrm{~cm})$.

The first separation each day was a partial separation, with each subject's being observed on different days. The second and third separations each day were always total separations, with the partners alternating as subjects. Thus, each monkey was observed during three total separations. The fourth and fifth separations each day were mirror-present separations, the precise condition being random with the constraint that each subject experience only one of each mirror-present test. Each test lasted $10 \mathrm{~min}$, after which the subjects were reunited and left for $1 \mathrm{~h}$ in the cage section in which the next test was to be conducted. There was always only one partition between the subject and the stimulus during any given test.

The following behavior patterns yielded significant effects in the analysis: visual exploration-eyes oriented toward the leftmost cage section, or the separated partner's cage section, depending upon the type of separation; locomotion-any walking, running, or climbing; vocalization-any vocalization; partition manipulation-physically contacting the transparent partition separating the subject from the leftmost cage section or the separated partner's cage section, depending upon the type of separation; social face-any facial expression not directed toward the experimenter and which would normally serve a communicatory function (e.8., lipsmacking, pouting). The following behavior patterns yielded no significant effects or occurred very rarely and, to save space, are not defined here: object manipulation, self-manipulation, inactivity, disturbance, autoeroticism, and drink. Mean scores were calculated for the three total separations experienced by each subject, and effects of the five types of separation were assessed by analyses of variance, with alpha $=.05$. Subsequent comparisons among means used the method of the least significant difference (LSD).

\section{Results}

The mean scores of the four animals in the five separation conditions are presented in Table 1 . The two behavior patterns most characteristic of the agitation or "protest" reaction to social separation, namely vocalization and locomotion (Harlow \& Suomi, 1974; Mineka \& Suomi, 1978), were most common in total separations, that is, when the subjects had neither the real partner nor the self-image available. Also, the mirror-far condition failed to reduce vocalization rate reliably below that recorded in total separations (LSD=63.6). During total separations, the subjects engaged in locomotion approximately $55 \%$ of the time, more than in any other condition $(L S D=11.4)$. Locomotion scores were similar among the other conditions.

The attractiveness of the social stimuli to the subject is clear from the visual exploration and partition manipulation scores, which were high and similar in partial separation and mirror-present tests. This suggests some degree of equivalence between the social partner and the self-image. However, the incidence of social facial expressions in the mirror-near condition was clearly higher than in the partial separation condition ( $\mathrm{LSD}=6.3$ ), indicating that the reflection was perceived to be different from the familiar cagemate. It was informally noted that the most common facial expression was lipsmacking, a gesture of affiliation or appeasement; it was virtually all directed to the stimulus.

These results suggest that, while MIS reduced separation-induced agitation in the infant monkeys and this reduction was comparable to that effected by the presence of the familiar cagemate, the emotional states associated with the two stimuli might have been different. Experiment 2 compared MIS with an unfamiliar live peer in similar circumstances, examining the effects of different rearing experiences

Table 1

Effects of Five Types of Separation Experience on Infants Living in Pairs

Separation Condition

\begin{tabular}{|c|c|c|c|c|c|c|}
\hline \multirow[b]{3}{*}{ Behavior } & \multirow[b]{3}{*}{ Total } & \multirow[b]{3}{*}{ Partial } & \multirow{2}{*}{\multicolumn{3}{|c|}{ Mirror }} & \multirow[b]{3}{*}{$\mathbf{F}$} \\
\hline & & & & & & \\
\hline & & & Near & Intermediate & Far & \\
\hline Vocalization & 158.3 & 43.3 & 79.0 & 92.8 & 116.5 & $4.3^{*}$ \\
\hline Locomotion & 54.6 & 42.4 & 35.6 & 41.2 & 42.8 & $3.5^{*}$ \\
\hline Visual Exploration & 9.8 & 25.3 & 31.5 & 20.9 & 28.9 & $8.1 \dagger$ \\
\hline Partition Manipulation & 5.4 & 15.6 & 13.2 & 9.6 & 10.9 & $3.5^{*}$ \\
\hline Social Face & .4 & 1.3 & 13.0 & 1.3 & 6.0 & $6.7 \div$ \\
\hline
\end{tabular}

Note-Vocalization and social face scores are frequencies; others are percentages of test time. For all results, $d f=4,12$.

${ }^{*} p<.05 . \quad t_{p}<.005$. 
of the subjects and employing a more sophisticated method of recording behavior.

\section{EXPERIMENT 2}

It is known that monkeys varying in early rearing experience react differently to MIS. For example, isolation-reared rhesus macaques show greater preference for their own mirror images than do groupreared rhesus (Gallup \& McClure, 1971). Montevecchi and Noel (1978) found that social facilitation of foodpecking was more rapid in pair-reared chicks tested with a mirror than in similarly tested isolation-reared chicks; group-reared chicks gave intermediate results. Thus, the novelty of the social stimulus was found to influence the subjects' reactions. The present experiment assessed mirror-directed responses in two groups of differentially reared infant monkeys, and considered whether the degree to which separated infants were placated by the presence of a mirror or an unfamiliar peer depended upon their rearing experiences.

\section{Method}

Subjects. Two groups of four mirror-naive stumptail macaques were used. The CONT group (two males, two females, mean age 11.5 months) had been reared continuously by their mothers in a group of adults, juveniles, and infants, before being housed together with an adolescent female in another room, 10 weeks before this experiment began. The SINOHALF group (one male, three females, mean age 8 months) consisted of two pairs. From the age of 2 weeks, each infant in this group had been housed with a single other infant for half of every day and housed alone for the other half. Thus, SINGHALF subjects had had experience with only one other monkey, whereas CONT animals had known many.

Apparatus. In a room unfamiliar to the subjects, two $51 \times 60$ $\times 69 \mathrm{~cm}$ cages were put side by side so that there was a clear view between them through transparent Perspex walls. Reactions to the stimuli were recorded on a 9-key keyboard linked to a "data transfer unit," which punched onto paper tape data coded by pressing sequences of keys on the keyboard. The tapes were later analyzed by computer to obtain rates, durations, and bout lengths of behavioral events. Vocalizations were counted on a hand tally. A $70 \times 70 \mathrm{~cm}$ mirror provided MIS. Two infant monkeys, one male and one female aged 9 and 11 months and unfamiliar to the subjects, served as stimulus animals. During the tests, the stimulus infants showed agitation at being separated from their own cagemates. Each stimulus infant was used once with each of two subjects from each group.

Procedure. Two days before the experiment began, each subject was given $1 \mathrm{~h}$ in one of the two cages, with a familiar peer visible in the other cage. Testing was then carried out over a 6-day period, with four subjects being tested once each per day. The subjects were given each of three 10-min conditions once: the neighboring cage empty; the neighboring cage containing an unfamiliar peer; and a mirror placed between the cages, blocking visual access to the neighboring cage but reflecting the subject's own image. The order in which the subjects experienced the three conditions was random, with the provision that a stimulus monkey was used only once on any day. Of the five behavior patterns recorded, submission, aggression, and play occurred too rarely to permit statistical analysis. To save space, they are not defined here. Exploration was divided into contact-touching and looking in the direction of the transparent partition separating the subject from the neighboring cage-and noncontact-eyes oriented toward the neighboring cage, no contact being made with the partition. Affiliation was also divided into contact-touching the partition while lipsmacking or pouting, or huddling against the partition- and noncontact-lipsmacking, teeth-chattering, or pouting in the direction of the neighboring cage and no contact being made with the partition. Exploration and affiliation scores were subjected to analyses of variance, with group as the between-subjects variable and condition and form (contact or noncontact) as within-subjects factors. Alpha was set at .05, and LSD values were calculated only for reliable ANOVA effects.

\section{Results}

There were no differences between the groups in overall responsiveness to any of the three conditions. Total social responses (the sum of all categories) were more frequent in the mirror and peer conditions than in the empty condition (mean rates of $43,50.5$, and 20.5 per $5 \mathrm{~min}$, respectively) and were more time consuming $(30.6 \%, 35.5 \%$, and $14 \%$, respectively) [rate, $F(2,12)=14.6, p<.001$; duration, $F(2,12)=12.0$, $\mathrm{p}<.005]$.

A significant group $\times$ condition interaction showed that vocal responses were different in the two groups $[F(2,12)=5.5, p<.025]$. SINGHALF monkeys gave significantly fewer vocalizations in the mirror and peer conditions (means of 9 and 5 , respectively) than in the empty condition (14), whereas CONT group's rate of vocalization averaged about 11 in all three conditions. Taking vocalization rate as an index of agitation, the two groups were equally agitated when the animals were alone, CONT animals were equally agitated in all three conditions, and SINGHALF subjects were at least partly calmed by the presence of an unfamiliar peer or a mirror.

There were too few agonistic episodes to merit statistical analysis, but three CONT animals behaved aggressively to the mirror, two doing so over 20 times in the 10-min tests, whereas only one SINOHALF subject exhibited one, brief threat to the mirror.

The three stimulus conditions elicited differing amounts of exploration: empty cage, $12.4 \%$; mirror, $19.2 \%$; peer, $31.0 \%[\mathrm{~F}(2,12)=14.2, \mathrm{p}<.001]$. As shown in Figure 1, rate of exploration in the three

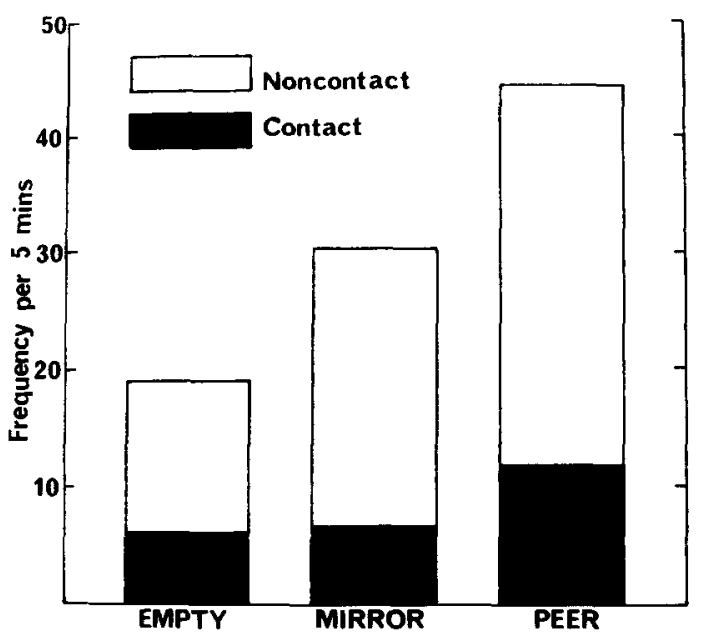

Figure 1. Rate of explorntion of three neighboring cage condltions in socially separnted infant monkeys. 


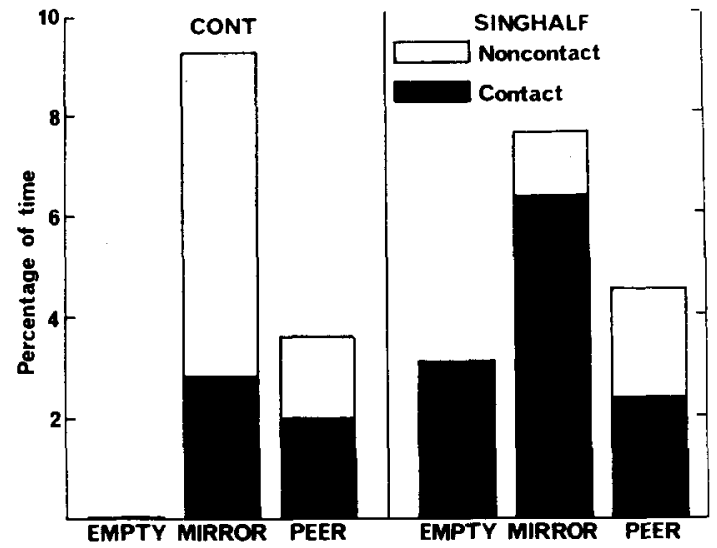

Figure 2. Amount of affiliation in three stimulus conditions by two groups of socially separated infant monkeys.

stimulus conditions also varied, with noncontact (i.e., visual) exploration occurring primarily with the unfamiliar peer, then with the mirror, then with the empty cage $[F(2,12)=4.8, p<.05]$. Overall, the CONT group spent slightly more time exploring the stimuli $(23.5 \%)$ than did the SINGHALF group $(18.2 \%)[\mathrm{F}(1,6)=5.9, \mathrm{p}<.05]$.

Figure 2 illustrates the most striking feature of the group $\times$ condition $x$ form interaction from the analysis of the percentage of time spent in affiliative responding in the three conditions $[F(2,12)=4.3$, $\mathrm{p}<.05]$. In both groups, the mirror received relatively high amounts of affiliation. In the CONT group, this took mainly such noncontact forms as pouting or lipsmacking, which can also be a gesture of appeasement. In the SINGHALF group, on the other hand, the mirror elicited contact affiliation, that is, huddling against the partition just in front of the mirror.

Considered with the other results, these differences in affiliation suggest that the SINGHALF subjects reacted in a conciliatory manner to MIS, whereas the CONT animals reacted more negatively.

\section{DISCUSSION}

In both experiments, the presence of strong social overtones in the responses of monkeys to mirrors was confirmed. Furthermore, the demonstration of a reduction of agitation in certain peer-separated infant monkeys represents an extension to nonhuman primates of a mirror-mediated social phenomenon established with domestic chicks (Gallup et al., 1972; Montevecchi et al., 1973). The correspondence between the findings seems even stronger, since the calming effect of a mirror occurred only in infants that had been housed with a single partner over a long period (compare with a study of chicks by Montevecchi \& Noel, 1978). This draws attention to the likelihood of diverging socioperceptual tendencies arising from variation in early rearing.

The question arises as to why the efficacy of MIS varied in reducing separation-induced protest in the monkeys. It seems unlikely that the pair-housed subjects were calmed by MIS because of any failure to detect a difference between their reflections and their real partners. For example, in Experiment 1, a nearby self-image received many more communicative signals than a nearby familiar cagemate. In Experiment 2, SINGHALF animals also discriminated between their own reflections and an unfamiliar peer, exploring the latter more, but engaging in more contact affiliation with the reflection. The "predictable" actions of the mirror image may have been more attractive to SINGHALF infants than CONT infants, the former having had more limited social experience (see Gallup \& McClure, 1971). It should be noted that, in studies of social facilitation in chicks, the relative roles of stimulus complexity and familiarity have not been adequately identified.

In contrast to SINGHALF monkeys, the more normally socially experienced CONT monkeys were placated by neither the unfamiliar peer nor the selfimage. The tendency of the group-reared infant monkeys to direct more appeasement and agonistic responses to a mirror, but to explore a live unfamiliar peer more, confirms that the stimuli differ in their social stimulus properties (see Gallup, 1968). It seems likely that a xenophobic component in the reaction of group-reared monkeys to the stimuli, especially to the mirror, was incompatible with a reduction in agitation during the separations.

In reacting to MIS, the subjects of Experiment 1 (group-reared, then housed in pairs) were more like the SINGHALF subjects of Experiment 2 than the CONT subjects (group-reared throughout infancy). This suggests that the attachment to the single cagemate in the subjects of Experiment 1 was a more important determinant of their behavior than was their earlier group-rearing experiences. That replacement attachment figures can strongly influence responses to stimuli has been shown by other authors (e.g., Chamove \& Harlow, 1975).

In another, unpublished experiment carried out by the author, adult female stumptail macaques showed nonsignificant increases in yawning, self-scratching, and threats to MIS. There was no evidence of reduced separation-induced agitation in the presence of the mirror, but self-grooming increased markedly. Interestingly, self-grooming also increases in adult stumptails tested with a live stimulus animal behind a clear partition (Goosen, 1974). This reinforces the notion that a mirror simulates a real social encounter to a certain extent. Systematic investigations into the development of mirror-image reactions in nonhuman primates, similar to those with humans (Lewis \& Brooks-Gunn, 1979), should increase knowledge of 
mechanisms involved in the perception of self and others.

\section{REFERENCES}

Anderson, J. R. Monkeys with mirrors: Some questions for primate psychology. International Journal of Primatology, in press.

Chamove, A. S. Rearing infant rhesus together. Behaviour, 1973, 47, 48-66.

Chamove, A. S., \& Harlow, H. F. Cross-species affinity in three macaques. Journal of Behavioural Science, 1975, 2, 131-136.

Cohen, P. S., \& Looney, T. A. Schedule-induced mirror responding in the pigeon. Journal of the Experimental Analysis of Behavior, 1973, 19, 395-408.

Davis, R. E., Harris, C., \& Sheldy, J. Sex differences in aggressivity and the effects of social isolation in the anabantoid fish, Macropodus opercularis. Behavioral Biology, 1974, 11, 497-509.

Dore, F., Lefebvas, L., \& Ducharme, R. Threat display in Betta splendens: Effects of water condition and type of agonistic stimulation. Animal Behaviour, 1978, 26, 738-745.

Galcup, G. G., Jr. Mirror-image stimulation. Psychological Bulletin, 1968, 70, 782-793.

GAlluP, G. G., JR. Mirror-image stimulation and tonic immobility in chickens. Psychonomic Science, 1972, 28, 257-259.

Gallup, G. G., JR. Self-awareness and the emergence of mind in primates. American Journal of Primatology, 1982, 2, 237-248.

Gallup, G. G., JR., \& Capper, S. A. Preference for mirrorimage stimulation in finches (Passer domesticus domesticus) and parakeets (Melopsittacus undulatus). Animal Behaviour, 1970, 18, 621-624.

Gallup, G. G., JR., \& MCCluke, M. K. Preference for mirrorimage stimulation in differentially reared rhesus monkeys.
Journal of Comparative and Physiological Psychology, 1971, 75, 403-407.

Gallup, G. G., Montevecchi, W. A., \& Swanbon, E. T. Motivational properties of mirror-image stimulation in the domestic chicken. Psychological Record, 1972, 21, 69-74.

Goosen, C. Immediate effects of allogrooming in adult stumptailed macaques, Macaca arctoides. Behaviour, 1974, 48, 75-88.

Hamrick, C., Cogan, D., \& Woolam, D. Social facilitation effects on runway and maze behavior in mice. Psychonomic Science, 1971, 25, 171-173.

HarLow, H. F., \& SuOMi, S. J. Induced depression in monkeys. Behavioral Biology, 1974, 12, 273-296.

Lewis, M., \& Brooks-Gunn, J. Social cognition and the aquisition of self. New York: Plenum Press, 1979.

LotT, D. F., \& Brody, P. N. Support of ovulation in the ring dove by auditory and visual stimuli. Journal of Comparative and Physiological Psychology, 1966, 62, 311-313.

Mine KA, S., \& Suomi, S. J. Social separation in monkeys. Psychological Bulletin, 1978, 85, 1376-1400.

Montevecchi, W. A., Gallup, G. G., Jr., Dunlap, W. P. The peep vocalization in group reared chicks (Gallus domesticus): Its relation to fear. Animal Behaviour, 1973, 21, 116-123.

Montevecchi, W. A., NoEL, P. E. Temporal effects of mirror-image stimulation on pecking and peeping in isolate, pair- and group-reared domestic chicks. Behavioral Blology, $1978,23,531$-535.

Suomi, S. J., Harlow, H. F., \& Domex, C. J. Effects of repetitive infant-infant separation of young monkeys. Journal of Abnormal Psychology, 1970, 76, 161-172.

Svendsen, G. E., \& Armitage, K. B. Mirror-image stimulation applied to field behavioral studies. Ecology, 1973, 54, 623-627.

(Manuscript received June 6, 1982;

revision accepted for publication November 17, 1982.) 